Çukurova Üniversitesi Mühendislik Mimarlık Fakültesi Dergisi, 34(3), ss. 207-217, Eylül 2019

\title{
Jet Lüle ile İklimlendirmesi Yapılan Bir Ofis Modelinde Konfor Seviyesinin (PMV/PPD) Sayısal Olarak Belirlenmesi
}

\author{
Alper YILDIRIM ${ }^{1}$, Coşkun ÖZALP ${ }^{* 2}$ \\ ${ }^{1}$ Osmaniye Korkut Ata Üniversitesi, Osmaniye Meslek Yüksek Okulu, Makine ve Metal \\ Teknolojileri Bölümü, Osmaniye \\ ${ }^{2}$ Osmaniye Korkut Ata Üniversitesi, Mühendislik Fakültesi, Enerji Mühendisliği Bölümü, \\ Osmaniye
}

Gelis tarihi: $18.02 .2019 \quad$ Kabul tarihi: 30.09 .2019

$\ddot{O} z$

$\mathrm{Bu}$ çalışmada, içerisinde insan, buzdolabı, lamba ve bilgisayar bulunan ve boyutları $3^{\times} 4^{\times} 3,5 \mathrm{~m}$ olan bir ofise jet lüle ile üfleme yapılmıştır. Ofisin Osmaniye ilinde yaz şartlarında olduğu varsayılmış ve içerisine \%100 taze hava verildiği düşünülerek 1sı kaybı kazancı hesabı yapılmıştır. Bu hesaba göre debi ve üfleme sıcaklığı bulunmuştur. Duvarlara, tabana, tavana 1sı kaybı ve kazancı hesabına göre 1S1 akısı verilmiştir. Ayrıca; insan, dolap, lamba ve bilgisayara 1sı akısı verilmiştir. Ofise yerleştirilen jet lülenin hız ve sıcaklık dağılımı ANSYS-FLUENT programı ile sayısal olarak elde edilmiştir. Sayısal hesaplamada sürekli koşullarda; kütlenin korunumu, türbülanslı momentumun korunumu, türbülans kinetik enerjisi $(\mathrm{k})$ ve türbülans kinetik enerjisinin yayınım hızı $(\varepsilon)$ denklemleri kullanılmıştır. Buradan elde edilen değerler ile zeminden 0,1, 0,6, 1,1 metre yüksekliğinde Isıl çevreden memnuniyet (Predicted Mean Vote-PMV) ve Isıl Çevreden Memnuniyetsizlik (Predicted Percentage Dissatisfied-PPD) değerleri hesaplanmıştır. Oluşturulan PMV ve PPD konturlarında jet lüle ile üfleme yapılan oda içerisindeki termal memnuniyet ve memnuniyetsizlik alanları tespit edilmiştir.

Anahtar Kelimeler: HVAC, Jet lüle, PMV, PPD

\section{Numerical Determination of Comfort Level (PMV/PPD) in an Office Model with Jet Nozzle}

\begin{abstract}
In this study, the air is blown to an office room which has dimensions $3^{x} 4^{x} 3,5 \mathrm{~m}$ by a jet nozzle. Office room includes a human, a refrigerator, a light and a computer, The office conditions were assumed to be in summer in Osmaniye province and the heat loss gain was calculated by considering $100 \%$ fresh air flow rate and blowing temperature were found according to this evaluation,. Heat flux is given to the all office walls with heat loss and gain calculation. The velocity and temperature distribution of the jet nozzle are simulated with the ANSYS-FLUENT program. The conservation of mass, the conservation of turbulent momentum, the kinetic energy of the turbulence $(\mathrm{k})$, and the velocity of propagation $(\varepsilon)$ of the kinetic energy of the turbulence equations are used. The Predicted Mean Vote (PMV) and Predicted
\end{abstract}

*Sorumlu yazar (Corresponding author): Coşkun ÖZALP, coskunozalp@osmaniye.edu.tr 
Percentage Dissatisfied (PPD) values at $0.1,0.6$, and 1.1 meters above the ground level of office were calculated from these values. The areas of thermal satisfaction and dissatisfaction in the room were determined with PMV PPD contours

Keywords: HVAC, Jet nozzle, PMV, PPD

\section{GİRIŞ}

Son yıllarda teknolojinin ilerlemesi ve çalışma şartlarının değişmesi ile birlikte insanların çalışma ortamları genellikle kapalı alanlar olmaya başlamıştır. Bu nedenle çalışma ortamındaki hava kalitesinin iyileştirilmesi insan konforu ve sağlı̆̆ açısından önem arz etmektedir. Insanların bulunduğu ortamın hava kalitesinin kötü olması sadece sağlık olarak değil, işyerinde verimsizlik, huzurlu çalışamama gibi etkilere de sebep olmaktadır. BS EN ISO 7730, termal rahatlığ "termal ortamdan memnuniyeti ifade eden zihnin durumu" olarak tanımlamaktadır, yani birisinin çok sıcak veya çok soğuk hissetmemesi durumu olarak tanımlamıştır. Termal konfor sadece sıcaklığa değil birçok etkene bağlıdır ve insandan insana değişiklik göstermektedir. Aynı odada bulunan iki kişiden biri terlerken diğeri üşüyebilir. $\mathrm{Bu}$ nedenle termal konfor için bir değer değil, ölçüm aralığı belirlenmiştir [1]. Termal konforu etkileyen faktörler çevresel ve kişisel faktörler olmak üzere ikiye ayrılmaktadır.

\subsection{Cevresel Faktörler}

- Hava Sıcaklığı: Bir kişinin temas ettiği havanın sıcaklığı, kuru termometre sicaklığı (DBT) ile ölçülür.

- Hava Hızı: Kişinin temas ettiği havanın hızı ( $\mathrm{m} / \mathrm{s}$ cinsinden ölçülür). Hava ne kadar hızlı hareket ederse, kişi ve hava arasındaki ısı değişimi o kadar büyük olur.

- Radyan Sıcaklık: Bir çevrenin sıcaklığı (yüzeyler, 1sı üreten ekipmanlar, güneş ve gökyüzü dahil) olarak ifade edilir. Bu genellikle ortalama radyan sicaklık (MRT, bir kişiyi çevreleyen yüzeylerin sıcaklığının ortalaması) ve güneşten gelen radyasyon gibi herhangi bir güçlü tek yönlü radyasyon olarak ifade edilir.

- Hava rutubeti (Hava nemi): Havadaki gerçek su buharı miktarı ve havanın o hava sıcaklığında tutabileceği maksimum su buharı oranı olarak tanımlanmakta ve yüzde olarak ifade edilmektedir.

\subsection{Kişisel Faktörler}

- Giyim: Kıyafetler, bir kişinin çevredeki hava ve yüzeyler ile ısı alışverişi yapmasının yanı sıra ter buharlaşması yoluyla 1sı kaybını etkilemesini sağlar. Kıyafetler bir kişi tarafından doğrudan kontrol edilebilir.

- Metabolik ısı: Fiziksel aktivite ile ürettiğimiz 1sıdır. Sabit bir kişi, egzersiz yapan bir kişiden daha soğuk hissetme eğiliminde olacaktır.

- Refah ve hastalıklar: $37^{\circ} \mathrm{C}$ bir vücut sıcaklığını muhafaza etme kabiliyetimiz olarak ifade edilmektedir.

Konforsuzluk durumu ısıl yüke bağlıdır ve konfor şartlarında ortalama deri sıcaklığı ve terleme miktarına sahip olan insan için; iç 1sı üretimi ile çevreye olan 1S1 kaybı arasındaki fark olarak tanımlanmıştır [2]. Büyük bir grubun 1sıl algılarını takip eden yedi noktalı 1sil duyarlılık derecelendirme ölçeği ile oluşturulan verilere göre PMV (Predicted Mean Vote) için bir denklem oluşturulmuştur. Çizelge 1'de termal konfor için 1sıl duyarlılık ölçeği ölçüm aralıkları ve Şekil 1'de PMV ve PPD (Predicted Percentage Dissatisfied) sayısal değerleri gösterilmektedir [3,4]. PPD konfor durumundan memnun olmayanların tahmini sayısını vermektedir.

Çizelge 1. Temal konfor için ısıl duyarlılık ölçeği ölçüm aralıkları [3,4]

\begin{tabular}{|c|l|}
\hline-3 & Soğuk \\
\hline-2 & Serin \\
\hline-1 & Biraz Serin \\
\hline 0 & Nötr \\
\hline 1 & Sicak \\
\hline 2 & Ilık \\
\hline 3 & Sicak \\
\hline
\end{tabular}




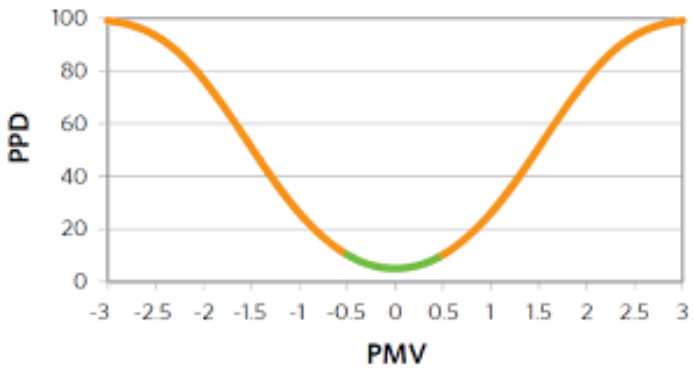

Şekil 1. PMV'nin fonksiyonu olarak PPD sayısal değerleri

İç ortam kabul edilebilir konfor aralıkları ASHRAE 55'de tek kategoride, ISO 7730'da A, B ve $C$ olarak üç kategoride belirtilmiştir. Bu değer aralıkları Çizelge 1'de verilmiştir [3,4]. Şekil 1 incelendiğinde en konforlu ortamda bile insanların yüzde 5'inin ortamdan memnuniyetsiz olduğu görülmektedir.

\section{2. ÖNCEKİ ÇALIŞMALAR}

Verimli bir HVAC sistem tasarımı, bir odadaki geometrik yapılandırma, iç ortam isı kaynaklarının dağıtımı ve iç ortamdaki termal koşullara göre besleme giriş ve egzoz çıkışının doğru şekilde yerleştirilmesini gerektirmektedir [5-9]. İç ortamın kalitesini iyileştirmek için kullanılan enerjideki artışla [10-12], kabul edilebilir bir kapalı ortamı korurken etkin havalandırma stratejileri kullanmak gerekir. Çoğu hava dağıtım sisteminde, havalandırma performansı ve enerji tasarrufu; besleme, geri dönüş ve egzoz difüzör konumlarının düzenlemelerinden büyük ölçüde etkilenmektedir [13].

Fong ve arkadaşları [9], bu sistemlerin kapalı termal ortam ve enerji tüketimi üzerindeki etkisini araştırmak için altı farklı egzoz yapılandırma ile üç farklı havalandırma sistemini kullanan deneysel bir çalı̧̧ma gerçekleştirmişlerdir. Elde edilen sonuçlar, egzoz açıklı̆ğ tavan seviyesinde (arka-orta seviye) konumlandığında, termal konforda önemli iyileşmelerin ve enerji tüketiminde azalma sağlandığını göstermektedir. Ayrıca Kuo ve Chung tarafindan [14], belirlenen bir alanda üfleme ve çıkış difüzör pozisyonlarının etkisini farklı havalandırma şartlarını kullanarak oda termal konforuna etkisini incelemişlerdir. Simülasyon sonuçlarına dayanarak, belirlenen alana üfleme havasının ne kadar uzun süre verilirse iç ortamdaki termal konforun o kadar iyi olduğunu tespit etmişlerdir. Daha sonra He ve diğerleri [6] egzoz havalandırma pozisyonunun hava akış modelini büyük ölçüde etkilemediğini, ancak iç ortamın maruz kalma seviyesini önemli ölçüde etkileyebileceğini belirtmişlerdir.

Liu ve Novoselac [15] çalışmalarında difüzör seçimi için bir Hava Yayılım Performans İndeksi (ADPI) modelini hava 1sitma modunda iken önermişlerdir. Modelde 1sıl çevreden memnuniyet (PMV) yöntemini ve iç ortam hava sıcaklı̆ğ ve hız arasındaki ilişkiyi geliştirmek için kullanılan ANSI/ASHRAE Standard-55 standardını uygulamışlardır. Çalışmalarında ayrıca yaygın olarak kullanılan 13 adet slot menfez türünün seçiminde kullanılmak üzere hava yayılım performans indeksi seçim rehberi geliştirmişlerdir.

Ahmad ve arkadaşları [16] kapalı soğutma alanı içinde dağıtım olan hava için üç boyutlu türbülanslı sirkülasyonunu teorik olarak incelemiş̧lerdir. Üç boyutlu bir bilgisayar programı (FLUENT6.3.26) kullanarak k- $\varepsilon$ ve SST k- $\omega$ yöntemleri ile odadaki karmaşık akışı modellemişlerdir. Irak için tasarım şartları ele alınmıştır. Çıkan teorik sonuçlar önceki yıllarda yapılan deneysel sonuçlarla doğrulanmıştır. Havalandırılan odadaki hava akımı slot, kare ve ızgara menfez kullanılarak hesaplanmıştır. Hesaplanan sonuçlarla ölçülen veriler karşılaştırıldığına basitleştirilmiş metodolojinin mühendislik uygulamalarında bir odadaki hava akımı ve sıcaklık tahmini için kullanılmasının iyi sonuçlar vereceğini belirtmişlerdir.

Hee-Jin Park [17] bir amfi ortamında, hem sicak hem de soğuk noktalar ve durgun alan bulunan bir akış modelini hesaplamalı akışkanlar dinamiği ile sayısal olarak göstermiştir. Çalışmada, üfleme ve emiş menfezlerinin doğru montaj yeri tespit edilmiş olup, bu sayede fazla hava akışının engellendiği vurgulanmıştır. 
Literatürde ofislerde ve iş merkezlerinde termal konforun incelenmesi ile ilgili çok sayıda çalışma mevcuttur. Memon ve arkadaşları [18] Pakistan'da bir üniversitenin sınıflarındaki termal konfor şartlarını soğutma yükü durumunda PMV modelini kullanarak değerlendirmiș ve insanların \%80'inden fazlasının konfor sıcaklığının $6,5{ }^{\circ} \mathrm{C}$ üstündeki 32,5 ${ }^{\circ} \mathrm{C}$ 'lik bir etkin sicakliktan memnun olduklarını ifade etmişlerdir. Stamou ve arkadaşları [19]), CFX CFD kodunu kullanarak Galatsi Arena stadyumunun içindeki üç boyutlu türbülanslı akış alanını hesaplamışlardır. Stadyumun farklı bölgelerinde PMV değerlerini sayısal olarak hesaplanan hiz ve sicaklık alanlarına bağlı olarak hesaplamışlardır. Song ve arkadaşları [20] Kore'de bir üniversite sinıfında bulunan split klimanın soğutma modundaki korelasyonunu öğrencilerin ortalama cilt sıcaklıkları üzerine çalışmışlardır. Öğrencilerin değişken oda sıcaklığını sabit bir sıcaklıkta tercih ettiklerini belirtmektedirler. Muhi ve Butala [21], PMV-PPD modelini uygulayan mekanik havalandırmalı idari ofislerde termal çevre ve hava kalitesi seviyesinin çalışanlar üzerindeki etkisini incelemişler ve çalışanlar ile memnuniyet anketi yapmışlardır.

\section{MATERYAL VE YÖNTEM}

\subsection{Sayısal Yöntem}

Sayısal çalışma üç boyutlu, zamandan bağımsız yaklaşımı kabulleri ile incelenmiştir. Sayısal analizde sonlu hacimler yöntemi ANSYS_FLUENT R 18.0 kullanılmıştır. Sonlu hacimler yönteminde, çözümü yapılacak model parçalara bölünerek bu parçaların her biri için çözüm yapma ve daha sonra bu çözümleri birleştirerek problemin genel çözümünü bulma esasına dayanmaktadır.

Hazırlanabilecek en uygun ağ yapısı için hız ve sıcaklık değişiminin fazla olduğu bölgelerde daha sık ağ yapısı oluşturulmalıdır. Bu nedenle, lülenin çıkış kısmı ile ofis modeli içerisinde bulunan geometriler çevresindeki yüzeyler en sık ağ yapısının olduğu kısımlardır ve diğer bölgelerde daha seyrek ağ yapısı tercih edilmiştir Ofis modelinin şematik gösterimi Şekil 2'de verilmiştir.

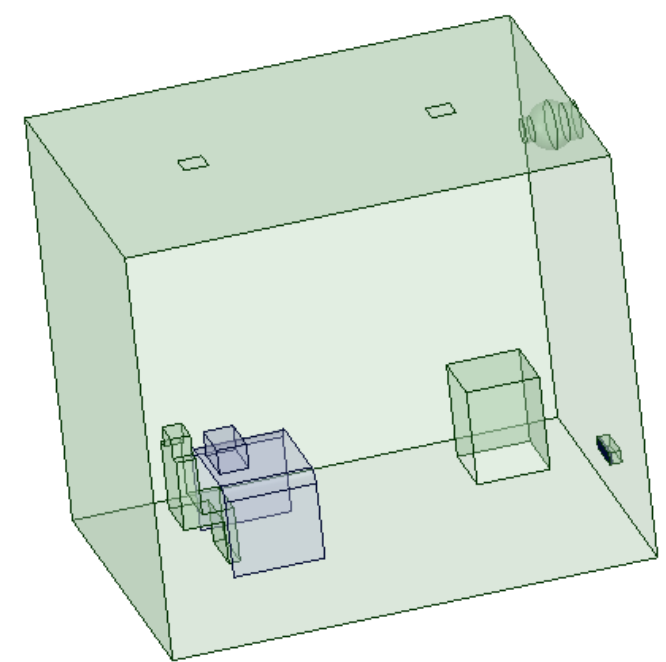

Şekil 2. Ofisin şematik gösterimi

Modellemesi yapılan ofisin ölçüleri Uzunluk (X) x Genişlik (Z) x Yükseklik (Y) = $4 \mathrm{~m}$ x $3 \mathrm{~m}$ x 3,5 m olarak seçilmiştir. Oda içerisinde insan, buzdolabı, lamba ve bilgisayar bulunduğu kabul edilmiştir. Bunların sayıları ve soğutma yükleri Çizelge 2'de verilmiştir. Ofiste kapı ve pencere bulunmadığı kabul edilmiştir.

Çizelge 2. Modellenen ofis odası için soğutma yükü.

\begin{tabular}{|l|c|}
\hline Isı Kaynă̆ı & $\begin{array}{c}\text { Soğutma Yükü̈ } \\
\left(\mathbf{W} / \mathbf{m}^{2}\right)\end{array}$ \\
\hline İnsan (ofiste oturan) & 70 \\
\hline Buzdolabı & 50 \\
\hline Lamba 2 & 15 \\
\hline Bilgisayar & 35 \\
\hline Batı Duvar & 4 \\
\hline Doğu Duvar & 20 \\
\hline Kuzey Duvar & 4 \\
\hline Güney Duvar & 21 \\
\hline Taban & 10 \\
\hline Tavan & 10 \\
\hline
\end{tabular}

Isı kaybı hesabına göre soğutma yükleri duvarlara verildiğinden duvarların sıcaklıkları aynı değildir. Batı ve kuzey duvar $27{ }^{\circ} \mathrm{C}$, güney ve doğu duvar $31{ }^{\circ} \mathrm{C}$, taban ve tavan $29{ }^{\circ} \mathrm{C}$ iç ortam $26{ }^{\circ} \mathrm{C}$ olmuştur. Oda içerisinde sıcaklık farkları 
olduğundan çözümde doğal konveksiyon oluşmuştur. Çalışmada $\mathrm{Ra}$ sayısının etkisi incelenmemiştir.

Bina yönüne göre soğutma yükü Çizelge 3'de verilen değerlere göre hesaplanmış ve buna göre de ofis duvarları, taban ve tavanına 1sı yükü verilmiştir. İnsan, buzdolabı, lamba ve bilgisayara soğutma yükleri ASHRAE temel el kitabından alınmıştır [22].

Çizelge 3. Yapı elemanlarının 1sı iletim katsayısı değerleri

\begin{tabular}{|l|c|c|c|}
\hline İşaret & Yön & $\mathbf{A}\left(\mathbf{m}^{\mathbf{2}}\right)$ & $\mathbf{U}\left(\mathbf{W} / \mathbf{m}^{\mathbf{2}} \mathbf{K}\right)$ \\
\hline Güney & $\mathrm{G}$ & 14 & 1,03 \\
\hline Batı & $\mathrm{B}$ & 10,5 & 1,03 \\
\hline Doğu & $\mathrm{D}$ & 10,5 & 1,93 \\
\hline Kuzey & $\mathrm{K}$ & 14 & 1,93 \\
\hline Tavan & & 12 & 1,2 \\
\hline Zemin & & 12 & 0,31 \\
\hline
\end{tabular}

Sayısal çözümleme için sabit referans hava giriş hızı $\left(V_{\text {in }}\right)=2,5 \mathrm{~m} / \mathrm{s}$ ve hava giriş besleme sıcaklığ $\left(\mathrm{T}_{\text {in }}\right)=286 \mathrm{~K}$ kabul edilmiştir. Diş hava sıcaklığ $311 \mathrm{~K}$ olarak alınmıştır. Bina yönüne göre soğutma yükü hesaplanmış ve buna göre de ofis duvarları, taban ve tavanına 1sı yükü verilmiştir.

Üç boyutlu Kartezyen koordinat sistemi türbülanslı, kararlı akış için korunum denklemleri aşağıda gösterilmiştir.

Süreklilik denklemi:

$\frac{\partial}{\partial \mathrm{x}_{\mathrm{j}}}\left(\rho \mathrm{u}_{\mathrm{i}}\right)=0$

Momentum denklemi:

$\frac{\partial}{\partial x_{j}}\left(\rho u_{i} u_{j}\right)=-\frac{\partial p}{\partial x_{i}}+\frac{\partial}{\partial x_{j}}\left[\mu \frac{\partial u_{i}}{\partial x_{j}}-\rho \overline{u_{i}^{\prime} u_{j}^{\prime}}\right]$

Burada $\rho$ akışkanın yoğunluğu, $u_{i}, x_{i}$ yönündeki ortalama hız bileşenlerini, $\mathrm{P}$ basınç, $\mu$ dinamik viskosite ve $u^{\prime}$ da hızın çalkantı bileşenidir. i ve j indisleri de her bir boyutu göstermektedir.
Enerji denklemi:

$\frac{\partial}{\partial \mathrm{x}_{\mathrm{i}}}\left(\rho \mathrm{u}_{\mathrm{i}} \mathrm{T}\right)=\frac{\partial}{\partial \mathrm{x}_{\mathrm{j}}}\left[\left(\frac{\mu}{\operatorname{Pr}}+\frac{\mu_{\mathrm{t}}}{\operatorname{Pr}_{\mathrm{t}}}\right) \frac{\partial \mathrm{T}}{\partial \mathrm{x}_{\mathrm{j}}}\right]$

Burada $\mu_{t}$ turbülans viskositesidir. $\mathrm{Bu}$ modelde türbülans stresi $-\rho \overline{u_{\imath}^{\prime} u_{\jmath}^{\prime}}$ 'nin de modellenmesi gerekir. Boussinesq yaklaşımı ile:

$-\rho \overline{u_{i}^{\prime} u_{j}^{\prime}}=\mu_{t}\left(\frac{\partial u_{i}}{\partial x_{j}}+\mu \frac{\partial u_{j}}{\partial x_{i}}\right)-\frac{2}{3}\left(\rho k+\mu \frac{\partial u_{i}}{\partial x_{i}}\right) \delta_{i j}$

Burada $\mathrm{k}$ türbülans kinetik enerjisidir ve $\mathrm{k}=\frac{1}{2} \overline{\mathrm{u}_{\mathrm{i}}^{\prime} \mathrm{u}_{\mathrm{j}}^{\prime}}$ ile ifade edilir. Bu çalışmada $\mathrm{k}-\varepsilon$ türbülans modelinin iyileştirilmiş duvar fonksiyonu kullanılmıştır. Türbülans kinetik enerjisi $(\mathrm{k})$ ve enerji yayınım oranı $(\varepsilon)$ aşağıdaki denklemlerde verilmiştir.

$\frac{\partial}{\partial \mathrm{x}_{\mathrm{i}}}\left(\rho \mathrm{ku}_{\mathrm{i}}\right)=\frac{\partial}{\partial \mathrm{x}_{\mathrm{j}}}\left(\alpha_{\mathrm{k}} \mu_{\mathrm{eff}} \frac{\partial \mathrm{k}}{\partial \mathrm{x}_{\mathrm{j}}}\right)+\mathrm{G}_{\mathrm{k}}-\rho \varepsilon$

$\frac{\partial}{\partial \mathrm{x}_{\mathrm{i}}}\left(\rho \varepsilon \mathrm{u}_{\mathrm{j}}\right)=\frac{\partial}{\partial \mathrm{x}_{\mathrm{j}}}\left(\alpha_{\varepsilon} \mu_{\mathrm{eff}} \frac{\partial \varepsilon}{\partial \mathrm{x}_{\mathrm{j}}}\right)+\mathrm{C}_{1 \varepsilon} \frac{\varepsilon}{\mathrm{k}} \mathrm{G}_{\mathrm{k}}-\mathrm{C}_{2 \varepsilon} \rho \frac{\varepsilon^{2}}{\mathrm{k}}-\mathrm{R}_{\varepsilon}$

Burada, $\alpha_{\mathrm{k}}$ ve $\alpha_{\varepsilon}$, RENG k- $\varepsilon$ türbülans modelinde $\mathrm{k}$ ve $\varepsilon$ için gerekli ters etkili Prandtl sayılarıdır. $G_{k}$ ortalama hız gradyanlarından dolayı oluşan türbülans kinetik enerjisidir ve aşağıdaki gibi bulunur:

$G_{k}=-\rho \overline{u_{i}^{\prime} u_{j}^{\prime}} \frac{\partial u_{j}}{\partial x_{i}}$

$\mu_{\text {eff }}$ efektif türbülans viskozitesi:

$\mu_{\text {eff }}=\mu+\mu_{\mathrm{t}}$

$\mu_{\mathrm{t}}$ türbülans viskozitesi

$\mu_{\mathrm{t}}=\rho \mathrm{C}_{\mu} \frac{\mathrm{k}^{2}}{\varepsilon}$

Sicaklık farklarından kaynaklanan hava yoğunluğundaki değişimi hesaplamak için Boussinesq varsayımı kullanılmıştır. Basınç ve hız 
bağlantısı için yarı örtülü basınca bağlı denklemlerde (SIMPLE) algoritması kullanılmıştır. Yakınsama kriteri olarak süreklilik ve momentum eşitlikleri için $10^{-4}$, enerji eşitliği içinse $10^{-7}$ alınmıştır.

Çalışmada elde edilen sonuçlarının ağ yapısından olan bağımsızlığını belirlemek için, Şekil 3'de gösterildiği gibi ağ eleman sayısı değiştirilerek faklı yükseklik sonuçların değişimi incelenmiştir. Üç farklı mesh sayısı kullanılarak sayısal çözümler elde edilmiştir. Oda içerisine 2,5 metre uzunluğunda "doğru” oluşturulmuş ve bu doğru üzerindeki 10 noktadaki sıcaklık değerleri alınmıştır. 3 farklı mesh sayısındaki geometrinin sayısal çözümünden alınan sıcaklık değerleri kıyaslanmıştır. Model kesitinde yaklaşık 3493152 adet elemanın olduğu ağ yapısının yeterli olduğu sonucuna varılmıştır. (4189324 adet elemanın olduğu sonuçlarla karşılaştırıldığında fark \%1 daha azdır).

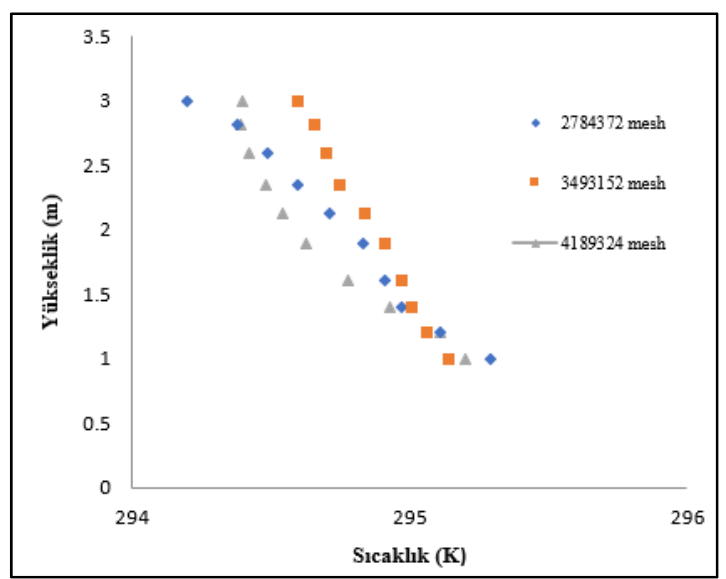

Şekil 3. Ağ bağımsızlığı

Şekil 4'te sayısal çalışmanın doğruluğunu göstermek için Parçacık görüntülemeli hız ölçme (PIV) tekniğini kullanılarak deneysel veriler elde edilmiş ve sayısal çalışma ile karşılaştırılmıştır. Sayısal çalışma ile deneysel çalışmanın karşılaştırılmasında geometrik ve Reynolds sayısının benzerliği kullanılmıştır. Re sayısı hesaplanırken lüle çapı esas alınmıştır. Benzerlik analizi sonuçlarına göre $\mathrm{Re}=41723$ olarak hesaplanmış ve doğrulmada akış hızı 3,09 m/s olarak bulunmuştur. Grafikten de görüldüğü gibi sonuçlar birbiriyle uyumludur ve bu nedenle sayısal sonuçların doğru ve kabul edilebilir olduğu sonucuna varılmıştır.

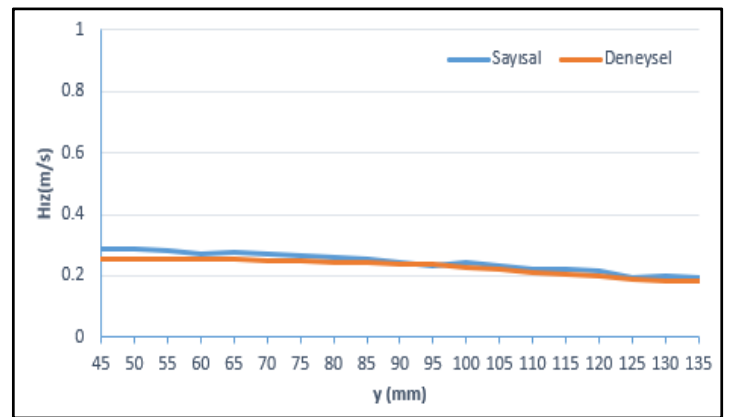

Şekil 4. Deneysel sonuçlar ile Sayısal sonuçların karşılaştırılması

\subsection{PMV ve PPD Değerlerinin Hesaplanması}

Isıl çevreden memnuniyet (Predicted Mean Vote PMV) ve Isıl Çevreden Memnuniyetsizlik (Predicted Percentage Dissatisfied-PPD) değerlerinin nasıl hesaplandığı, hesaplamalarda kullanılan semboller ve açıklamaları aşağıda belirtilmiştir.

M: Metabolik oran $\left(\mathrm{W} / \mathrm{m}^{2}\right)$

$\mathrm{W}$ : Efektif mekanik güç $\left(\mathrm{W} / \mathrm{m}^{2}\right)$

$\mathrm{I}_{\mathrm{cl}}:$ Kiyafet yalıtımı $\left(\mathrm{m}^{2} * \mathrm{~K} / \mathrm{W}\right)$

$\mathrm{f}_{\mathrm{cl}}$ : Kıyafet yalıtım faktörü

$\mathrm{t}_{\mathrm{a}}$ : Kuru hazne (hava) sicaklığ $1\left({ }^{\circ} \mathrm{C}\right)$

$\mathrm{t}_{\mathrm{r}}$ : Ortalama radyal sicaklik $\left({ }^{\circ} \mathrm{C}\right)$

$\mathrm{V}_{\mathrm{ar}}$ : Hava akım hızı $(\mathrm{m} / \mathrm{sn})$

$\mathrm{p}_{\mathrm{a}}$ : Kismi buhar Basinc1 $\left(\mathrm{p}_{\mathrm{a}}\right)$

$\mathrm{h}_{\mathrm{c}}$ : Konvektif 1si transferi katsayıs1 $\left(\mathrm{W} /\left(\mathrm{m}^{2} * \mathrm{~K}\right)\right.$

$\mathrm{t}_{\mathrm{cl}}$ : Kiyafet yüzey sıcaklığ $\left({ }^{\circ} \mathrm{C}\right)$

$\mathrm{PMW}=\left[0,303 \mathrm{e}^{-0,036 \mathrm{M}}+0,028\right] \times\{$

(M-W) $-3,05 \times 10^{-3}$

$\times\left[5733-6,99(\mathrm{M}-\mathrm{W})-\mathrm{p}_{\mathrm{a}}\right]-0,42$

$\times[(\mathrm{M} "-\mathrm{W})-58,15]-1,7 \times 10^{-5} \mathrm{M}(5867$.

$\left.p_{a}\right)-0,0014 M\left(34-t_{a}\right)-3,96$

$\left.\times 10^{-8} \mathrm{f}_{\mathrm{cl}} \times\left[\left(\mathrm{t}_{\mathrm{cl}}+273\right)^{-4}-(\overline{\mathrm{tr}}+273)^{-4}\right]-\mathrm{f}_{\mathrm{cl}} \mathrm{h}_{\mathrm{c}}\left(\mathrm{t}_{\mathrm{cl}}-\mathrm{t}_{\mathrm{a}}\right)\right\}$

$\mathrm{t}_{\mathrm{cl}}=35,7-0,028(\mathrm{M}-\mathrm{W})-$

$\mathrm{I}_{\mathrm{cl}}\left\{3,96 \times 10^{-8} \mathrm{f}_{\mathrm{cl}} \times\left[\left(\mathrm{t}_{\mathrm{cl}}+273\right)^{-4}\right.\right.$

$\left.\left.-(\operatorname{tr}+273)^{-4}\right]+\mathrm{f}_{\mathrm{cl}} \mathrm{h}_{\mathrm{c}}\left(\mathrm{t}_{\mathrm{cl}}-\mathrm{t}_{\mathrm{a}}\right)\right\}$ 


$$
\begin{aligned}
& \mathrm{h}_{\mathrm{c}}=\left\{\begin{aligned}
2,38\left(\mathrm{t}_{\mathrm{cl}}-\mathrm{t}_{\mathrm{a}}\right)^{0.25} & \text { için } 2,38\left(\mathrm{t}_{\mathrm{cl}}-\mathrm{t}_{\mathrm{a}}\right)^{0,25} \\
& >12,1 \sqrt{\mathrm{v}_{\mathrm{ar}},} \\
12,1 \sqrt{\mathrm{var}_{\mathrm{ar}}} & \text { için } 2,38\left(\mathrm{t}_{\mathrm{cl}}-\mathrm{t}_{\mathrm{a}}\right)^{0,25} \\
& <12,1 \sqrt{\mathrm{v}_{\mathrm{ar}},}
\end{aligned}\right\} \\
& \mathrm{f}_{\mathrm{cl}}=\left\{\begin{array}{l}
1,00+1,290 \mathrm{I}_{\mathrm{cl}} \text { için } \mathrm{I}_{\mathrm{cl}}<0,078 \mathrm{~m}^{2 \circ} \mathrm{c} / \mathrm{w}, \\
1,05+0,645 \mathrm{I}_{\mathrm{cl}} \text { için } \mathrm{I}_{\mathrm{cl}}>0,078 \mathrm{~m}^{2 \circ} \mathrm{c} / \mathrm{w},
\end{array}\right\} \\
& \mathrm{PPD}=100-95 * e\left(^{-0,3353 * P M V^{4}}-0,219 * P M V^{2}\right)
\end{aligned}
$$

\section{SONUÇ VE BULGULAR}

Ehab Foda ve Kai Sirén çalışmalarında [23] PMV PPD değerlerinin verilerini yerden $0,1,0,6$ ve 1,1 metre yükseklikte almışlardır. Bu çalışmada da benzer şekilde hız ve sicaklık değerleri kullanılarak PMV ve PPD değerlerinin verileri aynı yükseklikte hesaplanmıştır.

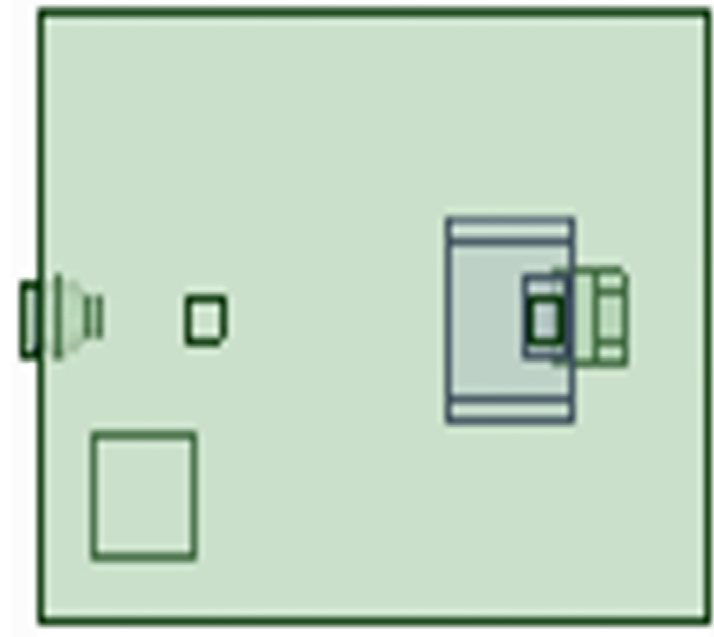

Şekil 5. Odanın üstten görünümü

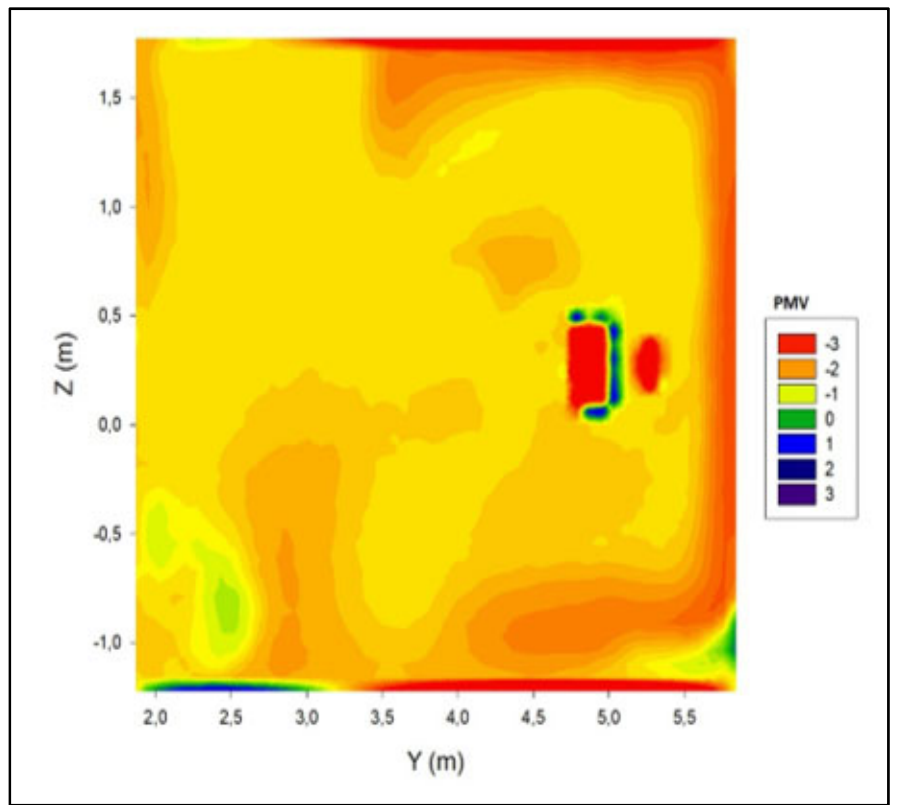

Şekil 6. Yerden 0,1 m yükseklik için PMV değeri

Şekil 6'da PMV değeri ofisin orta bölgelerinde -2,5 değerini almakta buzdolabının bulunduğu yer olan lülenin alt kısmında 0 ile $-1,5$ değerleri arasında değişmektedir. $\mathrm{Bu}$ nedenle PMV değerlerine göre ofisin orta kısımları çok serin diğer kısımları daha az serin bölgeleri göstermektedir. Lülenin etkisinin en az olduğu yer olan buzdolabının bulunduğu kısım diğer bölgelere göre termal konfora yakın serinliktedir. 


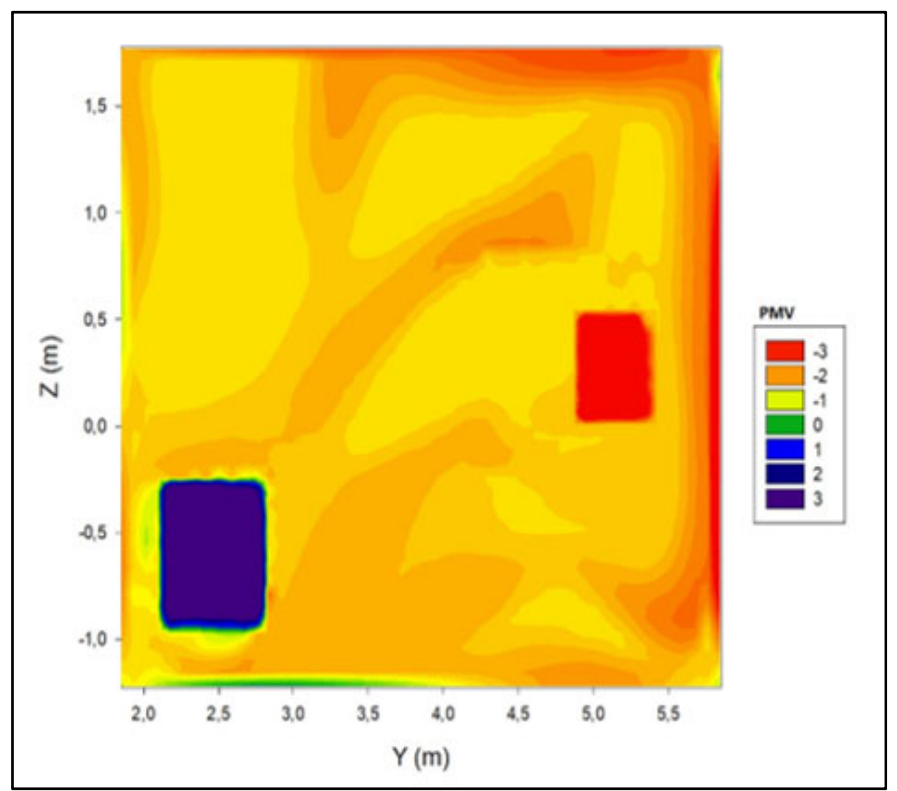

Şekil 7. Yerden 0,6 m yükseklik için PMV değeri

Şekil 7'de üflemenin olduğu yer çok serin, orta kısımlar serindir. Duvar kenarlarına yakın bölgeler nispeten konfor şartlarına yakındır. Buzdolabı olan yer termal konfordadir.

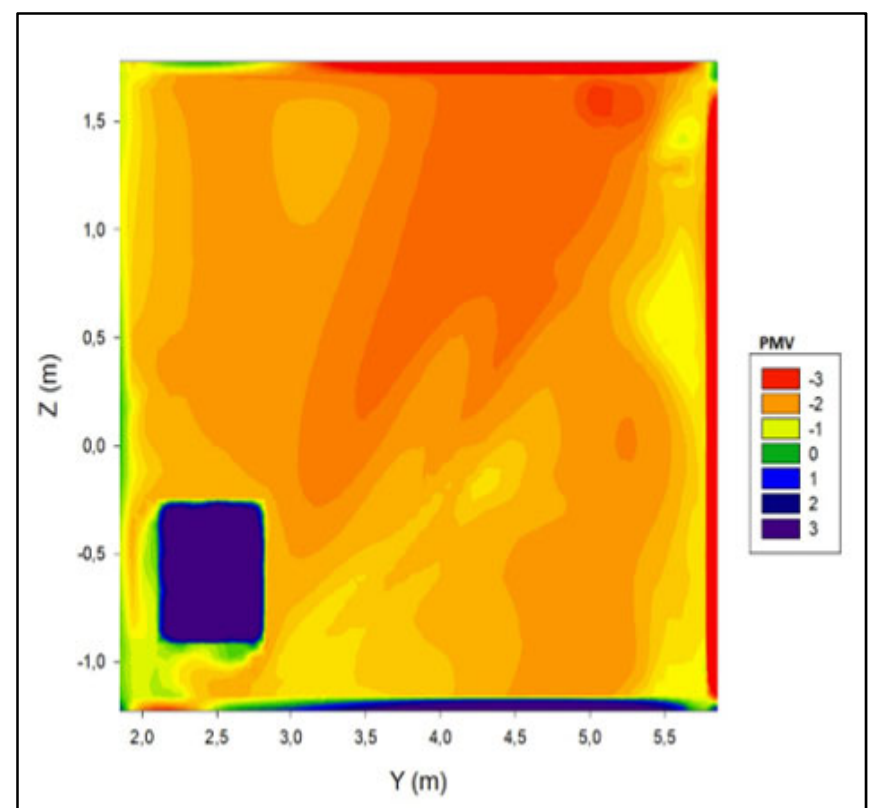

Şekil 8.Yerden 1,1 m yükseklik için PMV değeri

Şekil 8'de üflemenin olduğu yer ve orta kısımlar çok serindir. Duvar kenarlarına yakın bölgeler

nispeten serindir. 


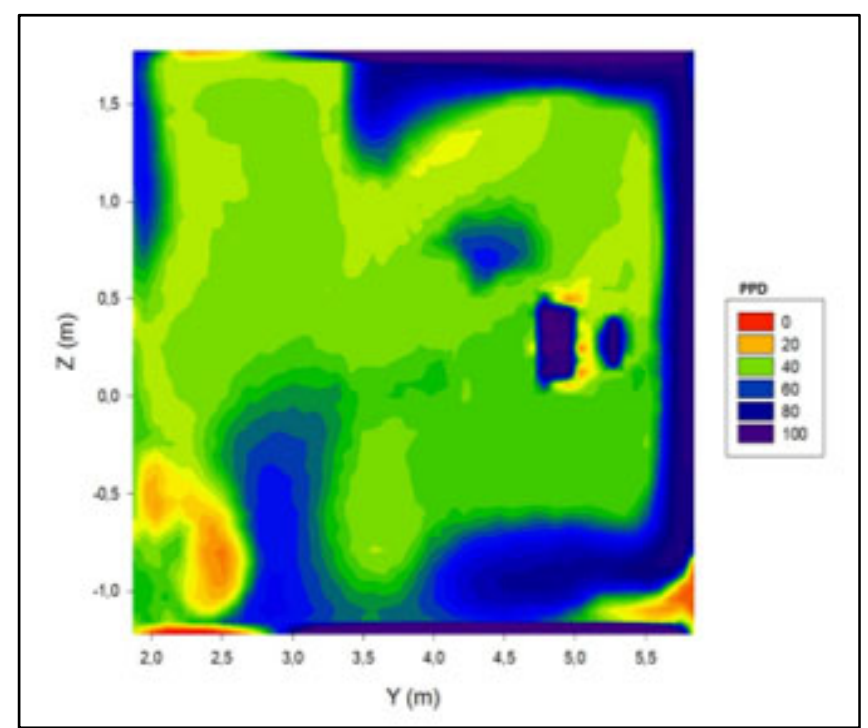

Şekil 9.Yerden 0,1 m yükseklik için PPD değeri

Şekil 9'da PPD değeri oda genelinde \%20 ile $\% 100$ arasında değişmektedir. Üflemenin olduğu kısımlarda \%20 ile \%50 arasındadır. Odanın orta kısımlarında PPD değeri \%80 ile \%100 arasında olup termal konfordan çok uzaktır. Duvar kenarlarında PPD değeri \%50 ile \%70 arasındadır.

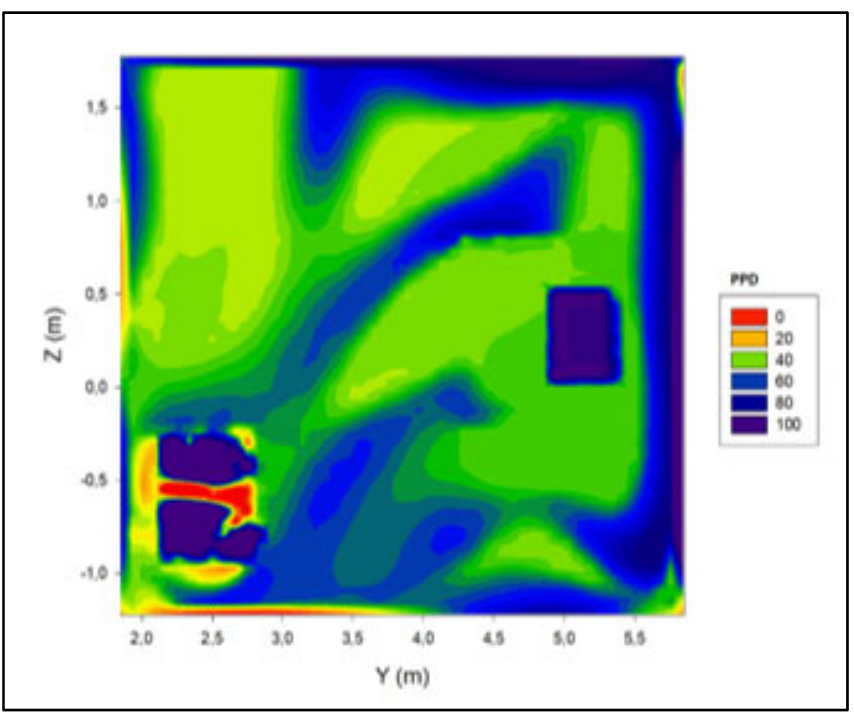

Şekil 10.Yerden 0,6 m yükseklik için PPD değeri

Şekil 10'da yerden 0,6 m yükseklik için PPD değerleri verilmiştir. Ofis genelinde $\% 0$ ile $\% 100$ arasında değişmektedir. Üflemenin olduğu kısımlarda PPD değeri \%0 ile idealdir. Odanın orta kısımlarında PPD değeri $\% 90$ ile $\% 100$ arasında olup termal konfordan çok uzaktır Duvar kenarlarında ise PPD değeri \%60 civarındadır. Bu yükseklik için ofisin bütününe yakın kısmında \%60 ve üzeri memnuniyetsizlik hesaplanmıştır. 


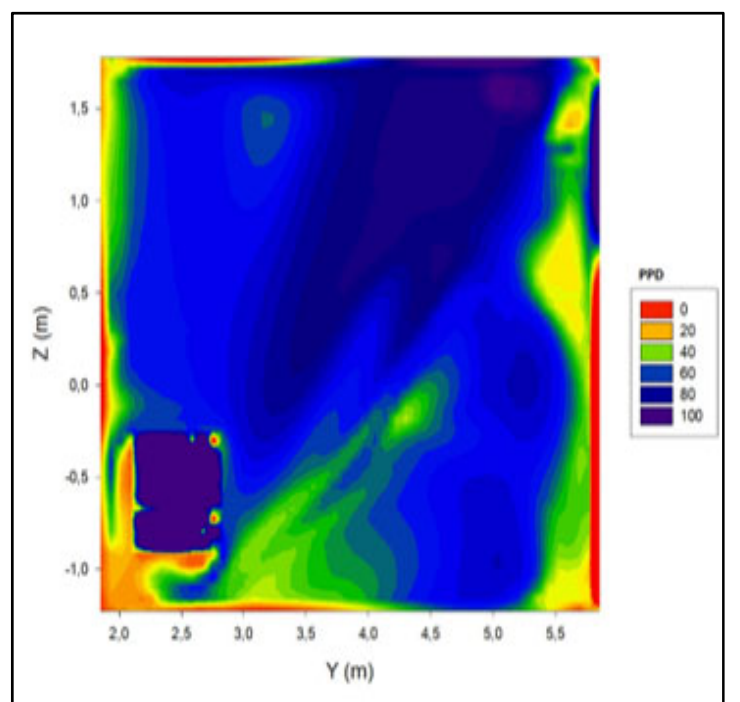

Şekil 11. Yerden 1,1 m yükseklik için PPD değeri

Şekil 11'de PPD değeri oda genelinde $\% 0$ ile $\% 100$ arasında değişmektedir. Üflemenin olduğu kısımlarda PPD değeri $\% 0$ ile idealdir. PNV değerinin $-1,0$ ile $-1,5$ olduğu bölgelerde diğer bölgelere göre memnuniyetsizlik oranı daha düşük çıkmıştır. 1,1 m yükseklik için ofisin büyük kısmında yüzde 50'nin üzerinde memnuniyetsizlik olduğu görülmektedir. Odanın orta kısımlarında PPD değeri $\% 90$ ile $\% 100$ arasında olup termal konfordan çok uzaktır. Duvar kenarlarında PPD değeri $\% 50$ ile $\% 70$ arasındadır.

\section{SONUÇLAR}

Isıl Çevreden Memnuniyetsizlik (Predicted PercentageD issatisfied-PPD) değerlerine bakıldığında genel olarak PPD değeri ofisin genelinde çok yüksektir. Bu da bize termal konfor şartlarını sağlanmadığını göstermiştir. Genel olarak PPD değerlerine bakıldığında orta bölgeler konfordan epey uzaktır. Isı akısının olduğu duvar ve buzdolabi gibi yerlerde termal konfora nispeten yaklaşılmıştır.

Sonuç olarak küçük ofis odaları için jet lülenin çok ideal menfez olmadığı anlaşılmıştır. Diğer menfez türleri ile sonuçlar kıyaslanırsa küçük boyuttaki ofisler için en uygun menfez seçilebilir.

\section{KAYNAKLAR}

1. https://www.designingbuildings.co.uk/wiki/Th ermal_comfort_in_buildings

2. Mihliyanlar, H., Kartal, S., Erten, Ş.Y., 2017. Yükseköğretim Yapılarında Isıl Konfor Şartlarının Araştırılması;Süleyman Demirel Üniversitesi Fen Bilimleri Enstitüsü Dergisi, 21(3), 917-927.

3. ASHRAE, ANSI/ASHRAE Standard 55, 2013. Thermal Environmental Conditions for Human Occupancy, American Society of Heating, Ventilating and Air-conditioning Engineers, Atlanta.

4. ISO Standard 7730, 2005. Ergonomics of the Thermal Environment-analytical Determination and Interpretation of Thermal Comfort Using Calculation of the PMV and PPD Indicesand Local Thermal Comfort Criteria, International Organisation for Standardisation, Genova

5. Parsons, K., Human, 2002. Thermal Environments, the Effects of Hot Moderate and Cold Environments on Human Health, Comfort, and Performance, Third Edition, CRC Press, Taylor\&Francis Group. 257-268.

6. He, G., Yang, X., Srebric, J., 2005. Removal of Contaminants Released from Room Surfaces by Displacement and Mixing Ventilation: Modeling and Validation. Indoor Air. 15, 367-380.

7. Budaiwi, I., Abdou, A., 2013. HVAC System Operational Strategies for Reduced Energy Consumption in Buildings within Termitten Occupancy: the Case of Mosques. Energy Conversion and Management. 73, 37-50.

8. Schiavon, S., Melikov, A.K., Sekhar, C., 2010. Energy Analysis of the Personalized Ventilation System in Hot and Humid Climates. Energy and Buildings, 42, 699-707.

9. Fong, M., Hanby, V., Greenough, R., Lin, Z., Cheng, Y., 2015. Acceptance of Thermal Conditions and Energy Use of Three Ventilation Strategies with Six Exhaust Configurations for the Classroom. Building and Environment, 94, 606-619.

10. Salvalai, G., Pfafferott, J., Sesana, M.M., 2013. Assessing Energy and Thermal Comfort of Different Low-energy Cooling Concepts for 
Non-residential Buildings, Energy Conversion and Management, 76, 332-341.

11. Wong, L., Mui, K., 2009. An Energy Performance Assessment for Indoor Environmental Quality (IEQ) Acceptance in Air-conditioned Offices. Energy Conversion and Management, 50, 1362-1367.

12. Kharseh, M., Altorkmany, L., Al-Khawaj, M., Hassani, F., 2014. Warming Impact on Energy Use of HVAC System in Buildings of Different Thermal Qualities and in Different Climates. Energy Conversion and Management, 81, 106-111.

13. Ahmed, A.Q., Gao, S., 2015. Thermal Comfortand Energy Saving Evaluation of a Combined System in an Office Room Using Displacement Ventilation, World Academy of Science, Engineering and Technology International Journal of Mechanical and Mechatronics Engineering, 9(6).

14. Kuo, J.Y., Chung, K.C., 1999. The Effect of Diffuser's Location on Thermal Comfort Analysis with Different Air Distribution Strategies. Journal of Building Physics. 22, 208-29.

15. Liu, S., Novoselac, A., 2015. Air Diffusion Performance Index (ADPI) of Diffusers for Heating Mode Building and Environment, 87, 215-223.

16. Ahmad, S.T., Mahdi, A.A., Husein, H.M.A., 2013. A Theoretical Study for Cold Air Distribution to Different Supply Patterns, International Journal of Engineering Technology IJET-IJENS 13, 04.

17. Park, H., 2005. CFD Analysis Assists in Optimization of Thermal Displacement Ventilation for an Elementary School Auditorium, Design Solution Section, HPAC Engineering.

18. Memon, R., Chirarattananon, S., Vangtook, P., 2008. Thermal Comfort Assessment and Application of Radiant Cooling: A Case Study. Building and Environment, 43(7), 1185-1196.

19. Stamou, A.I., Katsiris, I., Schaelin, A., 2008. Evaluation of Thermal Comfort in Galatsi Arena of the Olympics "Athens 2004" Using a CFD Model. Applied Thermal Engineering 28(10), 1206-1215.
20. Song, G.S., Lim, J.H., Ahn, T.K., 2012. Air Conditioner Operation Behaviour Based on Students' Skin Temperature in a Classroom. Applied Ergonomics 43(1), 211-216.

21. Muhio, S., Butala, V., 2004. The Influence of Indoor Environment in Office Buildings on Their Occupants: Expected-unexpected. Building and Environment, 39(3), 289-296.

22. ASHRAE Handbook 1997. Fundamentals, Nonresidential Cooling and Heating Load Calculations, Atlanta, USA.

23. Foda, E., Sirén, K., 2014. Evaluating the Thermal Comfort Performance of Heating Systems Using a Thermal Manikin with Human Thermo Regulatory Control, 25(1), 191-202. 
